\title{
Emakumezkoaren gernu-inkontinentzia
}

\author{
Urinary incontinence in women \\ Maider Andres Arribalzaga \\ Gurutzetako Unibertsitate Ospitalea \\ mandresa@sego.es
}

\section{Laburpena}

Emakumezkoetan gernu-inkontinentzia (GI) sarritan agertzen den osasun-arazo bat da, haien bizikalitatea sendo asaldatzen duena; halere, lotsa edota informazio faltagatik ia erdiek ez dute kontsultatzen. Gernu-inkontinentzia mota ezberdinak daude eta horien artean bi dira nagusiak: premiazko gernu-inkontinentzia (PGI) eta estresagatiko gernu-inkontinentzia (EGI). Bai ginekologoak bai urologoak azter dezake arazo hau eta beharrezko ikerketa burutu ondoren tratamendu egokiena ezarri; hasteko teknika kontserbatzaileak erabiltzen dira, zeinak zoru pelbikoko muskuluen indartzean, gernu-maskuriaren heziketan edota eguneroko bizi-ohiturak aldatzean oinarritzen diren. Horiek porrot egiten badute, inkontinentzia motaren arabera tratamendu ezberdinak daude. PGlan tratamendu farmakologikoa erabil dezakegu, antimuskarinikoak edota beta 3 agonista adrenergikoak hain zuzen. EGlaren kasuan, ostera, kirurgiara joko dugu; badaude horretarako hainbat teknika, urteetan zehar hobetuz joan direnak, gaur egun erabiliena uretra azpiko xingolak direlarik, polipropilenozkoak. Xingolen eraginkortasun-tasa altua da, mota ezberdinak daude bakoitza bere berezitasunekin eta horiek ezagutzea ezinbestekoa da pazienteari aholku egokiena emateko. Beraz funtsezkoa da emakumeek jakin dezaten gernu-inkontinentzia ez dela zahartzearen ondorio normal bat eta badaudela horretarako konponbideak.

Gako-hitzak: gernu-inkontinentzia, zoru pelbikoa, inkontinentziarako kirurgia

\section{Abstract}

Urinary incontinence (UI) in women is a common health problem that strongly affects their quality of life. However, almost $50 \%$ of those affected do not seek care due to embarrassment or lack of information. The main types of urinary incontinence are urge urinary incontinence and stress incontinence. Incontinence can be treated by a gynecologist or urologist, both of whom are qualified to choose the most adequate treatment for each patient after a correct study. For treatment, we generally begin with conservative techniques, for example: pelvic floor muscle strengthening exercises, reeducation of urinary bladder or modification of daily lifestyle. If this treatment is not effective, there are different options depending on the type of incontinence. In the case of urge urinary incontinence, we apply pharmacologic treatment, with anti-muscarinic or beta agonist drugs. On the other hand, for stress $\mathrm{UI}$, we generally opt for surgery. A variety of different surgical techniques have evolved in recent years, with mid-urethral slings made from polypropylene being the most common option. The efficacy of surgery for stress $\mathrm{UI}$ is high; each sling type has different characteristics, so it is very important to be well informed about them in order to be able to give the best advice to the patient. It is fundamental for women to know that $\mathrm{UI}$ is not a normal consequence of age and that there are many solutions available for this health problem.

Key words: urinary incontinence, pelvic floor, surgery for incontinence 
Bidalia: 2018-09-23

Onartua: 2018-11-26

http://doi.org/10.26876/osagaiz.2.2018.186

\section{Definizioa}

Gernu-inkontinentzia nahigabeko gernu-galerari deritzogu.

\section{Gernu-inkontinentzia motak}

2.1. Estresagatiko gernu-inkontinentzia (EGI): esfortzu batekin erlazionaturiko nahigabeko gernugalera, hala nola aktibitate fisikoarekin, eztula edo doministiku egitearekin (1).

Esfortzu bat egitean sabel barneko presioa handitzen da eta uretrako esfinterrak, normalki presio hori jasaten duenak, EGlan ezin du jasan eta ez da behar bezala itxita mantentzen. Baliteke uretraren hipermobilitateak ere zerikusia izatea gernu-galera mota honetan.

2.2. Premiazko gernu-inkontinentzia (PGI): nahigabeko gernu-galera gernu egiteko premiazko sentsazioarekin erlazionatuta dagoenean. Emakumeak bat-bateko gernu egiteko behar bortitza sentitzen du eta ezin du atzeratu (2). Gernu egiteko premiazko sentsazio hori "gernu-maskuri hiperaktiboaren sindromea»ren sintoma nagusia da; gainera, honako hauek ere ager daitezke: PGla, hau da, premiazko sentsazio horrekin erlazionaturiko nahigabeko gernu-galera, eta gernu egiteko maiztasunaren handitzea, bai egunez edo bai gauez ere (azken kontzeptu horri nokturia deritzo).

Premiazko inkontinentzian, hau gertatzen da: gernu-maskuriaren detrusore izeneko muskulua uzkurtu egiten da puxika beteta egon ez arren, normalki alderantziz gertatzen denean; hau da, maskuria beteta dagoenean gernu egiteko sentsazioa izaten dugu eta, komunera joatean, gernu egiteko momentuan uzkurtzen da muskulu detrusore hori.

\subsection{Gernu-inkontinentzia mistoa (GIM): aurreko biak batuta daudenean.}

2.4. Beste batzuk: adibidez gainezkako gernu-inkontinentzia; etengabeko gernu-inkontinentzia gernu-maskuriaren hustuketa eskasagatik. EGI eta PGlaren sintomekin batera ager daiteke.

\section{Garrantzia}

Gernu-inkontinentzia gutxi kontsultatzen eta tratatzen den patologia bat da, ohikoa izan arren. Gutxi gorabehera emakumezkoen \%50ek pairatzen du gernu-inkontinentzia, eta horietatik soilik \% 2561ek kontsultatzen du (3). Sarritan pazienteak ez daude beren gernu-inkontinentzia eta txizaren inguruko sintomei buruz hitz egiteko prest, lotsagatik, tratamendurako aukeren ezagutza faltagatik edota kirurgiaren beldur direlako.

Haien bizi-kalitateari eragiten dioten nahigabeko gernu-galera edota txizaren inguruko arazoez galdetzeak ginekologoaren egunerokotasunaren parte bat izan behar du.

Gernu-inkontinentzia ez da hilkortasunarekin erlazionatzen, baina emakumezkoaren osasunarekin zerikusia daukaten arlo askotan eragin dezake:

3.1. Bizi-kalitatea: gernu-inkontinentzia depresioarekin eta urduritasunarekin erlazionaturik dago, baita lan-aktibitatearen narriatze eta baztertze sozialarekin ere (4).

3.2. Sexu-disfuntzioa: inkontinentzia koitala inkontinentziadun pertsonen herenean agertzen da, sexu-harremanetan gernu-galera izateko beldurrarekin batera. Horrek guztiak bizitza sexuala kaltetzen du. 
3.3. Erikortasuna. Perineoko infekzioak ager daitezke hezetasunagatik, baita lurrera erortzea eta ondoriozko hezur-hausturak ere, zeintzuek aldi berean erikortasuna eta hilkortasuna handitzen duten, baita osasun-gastuak ere (5).

\section{Epidemiologia eta etiologia}

Badaude hainbat faktore gernu-inkontinentziarekin erlazionaturik:

4.1. Adina: adina aurrera doala, bai inkontinentziaren prebalentzia eta bai larritasuna ere handitu egiten dira.

4.2. Obesitatea gernu-inkontinentzia pairatzeko arrisku-faktore indartsua da, eta hirukoiztu egiten du arrisku hori (6). Behaketa-ikerketa ugarik \%50 edo gehiagoko murrizketa argitaratu dute estresagatiko gernu-inkontinentzian, kirurgia bariatrikoaren ondorengo pisu-galeraren ondorioz (7).

4.3. Erditze kopurua: erditze kopuru handia arrisku-faktorea da bai gernu-inkontinentziarako eta bai prolapso genitalarentzako. Halere, inoiz erditu gabeko emakumezkoek ere beren bizi-kalitatea erasaten duen gernu-inkontinentzia adierazten dute, 55 eta 64 urteen bitarteko emakumezkoen $\% 32$ erasanda izanik (8).

4.4. Erditze mota: estresagatiko gernu-inkontinentziari dagokionez, zesarea bidez erditu duten emakume erditze baginala izan dutenek baino tasa baxuagoa aurkezten dute, nahiz eta zesareak ez duen EGIganako babesa ematen.

4.5. Familiako historia: batez ere premiazko gernu-inkontinentziaren kasuan, paziente hauetan arriskua altuagoa izan daiteke.

4.6. Etnia: ez dago argi arrazen arteko diferentziarik dagoen ala ez.

4.7. Beste batzuk: tabakoa erretzea, kafeinaren kontsumoa, diabetesa, iktusa, depresioa, uzkiko inkontinentzia, gernu- edo ugal-aparatuetako ebakuntza (histerektomia edo umetokiaren erauzketa adibidez), eta irradiazioa.

4.8. Estresagatiko gernu-inkontinentzia ariketa fisiko bortitzarekin erlazionatzen da, adibidez saltoka edo korrika egitea; bestalde premiazko gernu-inkontinentzia bikoterik ez izatearekin, gernuinfekzio errepikatuak izatearekin eta umezaroan gernu-aparatuaren inguruan izandako sintomatologiarekin (enuresia barne) erlazionatzen dira.

4.9. Dementzia: \% 10-38ko prebalentziarekin agertzen da gernu-inkontinentzia.

\section{Diagnostikoa}

Oinarrizko ebaluazioa emakumezko guztiekin egingo dugu eta batzuetan, gainera, aurkikuntzen arabera, ebaluazio espezializatua ere egin beharko da.

\subsection{Oinarrizko ebaluazioa}

Gernu-inkontinentziaren arrisku-faktoreak eta larritasun-sintomak edo zeinuak identifikatuko ditugu. Bizi-kalitatean duen eragina aztertzea ezinbestekoa da.

Funtsezkoa da gernu-inkontinentziaren arrazoi izan daitezkeen patologia organikoa edota gernuinfekzioa baztertzea.

\subsubsection{Arrisku-faktoreen ezagutza}

Anamnesi orokorra egingo dugu, arrisku-faktore aldakorrak dauden ikusteko edota sintomak okertzen dituen farmakoren bat hartzen duen jakiteko.

Emakumezko gazteetan eta adin ertainekoetan, soilik adina, Barneko Masa Indizea (BMI), erditze kopurua eta mota daude gernu-inkontinentziarekin nabarmenki asoziaturik, are gehiago EGlarekin.

Gla kaltetzen duten botikak (1. taula) 
1. taula. Gla eragin edo okertzen duten farmakoak

\begin{tabular}{|ll|}
\hline Substantzia & Mekanismoa eta inkontinentzia-sintoma \\
Antidepresiboak & Puxikaren uzkurtzea gutxitzen dute: erretentzioa, gainezkako Gla \\
Diuretikoak & Diuresia handitzeagatik uzkurdurak: PGla \\
Lasaigarri eta hipnotikoak & Depresio zentrala: PGla \\
Antipsikotikoak & Puxikaren uzkurdura gutxitzen dute: erretentzioa eta gainezkako Gla \\
Alkohola & Depresio zentrala eta eragin diuretikoa: PGla \\
Kafeina & Uzkurdurak: PGla \\
\end{tabular}

Farmako horiek gernu-inkontinentzian eragin dezakete, beraz anamnesian horien kontsumoa aztertzea garrantzitsua da.

\subsubsection{Galdera gakoak}

Gernu-inkontinentzia mota bakoitza adierazten duten sintomen balioespenera zuzenduta daude.

\section{Gernu-inkontinentziaren diagnostikorako galdera gakoak.}

\section{EGlaren sintomak}

Eztul egin, doministiku egin edota pisuak altxatzean txizaren galera nabaritzen duzu?

\section{PGlaren sintomak}

Noizbait, gernu egiteko bat-bateko sentsazio kontrolaezina nabaritzen duzunean txiza galtzen al duzu?

\section{Glarekin erlazionaturiko sintomak}

Noizbait sentitzen al duzu gernu egiteko gogo handi atzeraezina?

Zenbat aldiz egiten duzu txiza egunero?

Zenbat denbora, gehiengoz jota, irauten duzu txiza egin gabe? (gernu-maiztasuna)

Zenbat alditan esnatzen zaitu txizagurak loaldian? (nokturia)

\section{Hustuketa-disfuntzioaren sintomak}

Puxika guztiz husten ez duzulako sentsazioa izaten al duzu? (hustuketa ez-osoa)

\section{Inkontinentziaren larritasunarekin erlazionaturiko sintomak}

Tantak galtzen al dituzu edota asko bustitzen zara?

Gernu-inkontinentziarako babes-sistemaren bat erabiltzen duzu? Zenbat alditan aldatzen zara egunero? 
Sandvik-en larritasun-testa, erdaraz balioztatua (2. taula)

2. taula. Sanvik-en larritasun-testa

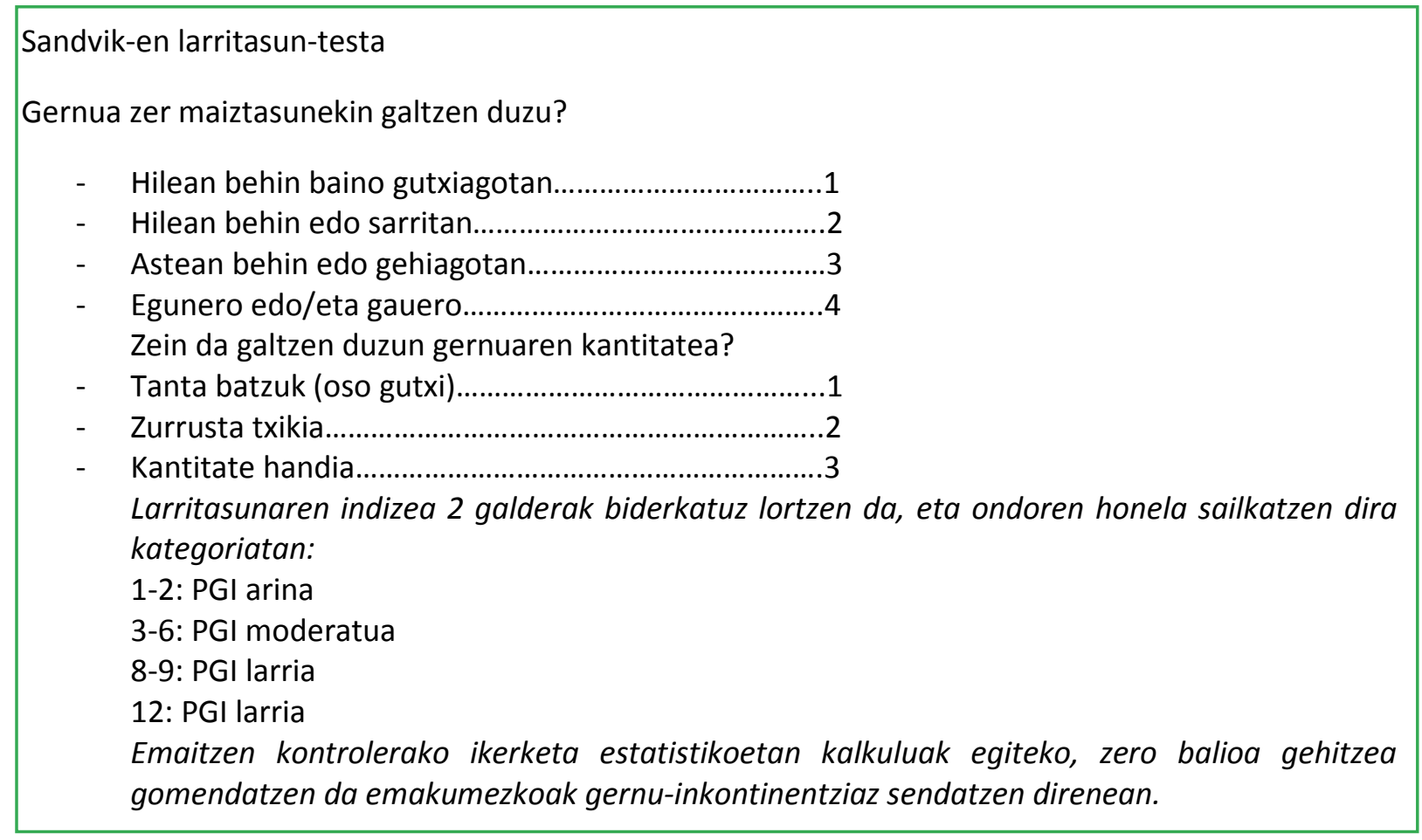

Inkontinentziaren larritasuna aztertzeko galdeketa egin ostean, puntuazio ezberdin bat lortzen da.

Glarekin erlazionaturiko zoru pelbikoaren beste disfuntzio batzuen sintomak identifikatzea garrantzi handikoa da, hau da, prolapsoa, uzki-inkontinentzia, min pelbikoa eta sexu-disfuntzioak. Horri buruz galdetuko diegu pazienteei.

\subsubsection{Galdeketak}

Sintomen galdeketa estandarizatuak ditugu, alde batetik, GI mota identifikatzen lagunduko digutenak, eta, bestetik, pazienteen bizi-kalitatean duten eragina baloratzekoak. Adibidez, "King's Health Questionaire» eta "Cuestionario corto de calidad de vida de la International Consultation on Incontinence (ICIQ-SF)» (3. taula).

Bizi-kalitatea PGlarekin gehiago kaltetu ohi da EGlarekin alderatuz gero. 
3. taula. ICIQ-SF («International Consultation on Incontinence»ren bizi-kalitateari buruzko galdeketa laburra)

«International Consultation of Incontinence»ren bizi-kalitateari buruzko galdeketa laburra (ICIQ-IU-SF) »

ICIQ-IU-SF

DATA: EGUNA _ HILA _ URTEA

Mesedez, idatz ezazu zure jaioteguna: EGUNA _ HILA _ URTEA _

1- Zu zara? (esan zein) emakumezkoa _ gizonezkoa

2- Zer maiztasunekin galtzen duzu gernua? (adierazi bat)

Inoiz ez

0

Astean behin edo gutxiagotan $\quad-1$

Astean bi edo hirutan $\quad$ _ 2

Egunean behin $\quad 3$

Egunean behin baino gehiagotan _ـ 4

Etengabe $\quad$ _5

3- Galtzen duzun gernu-kantitateari buruz duzun sentsazioa jakin nahiko genuke. Normalki galtzen duzun gernu-kantitatea (babesleak eraman zein ez eraman) (adierazi bat)

Ez dut ezer galtzen $\quad-0$

Oso kantitate gutxi _- 2

Bitarteko kantitatea $\quad-4$

Kantitate handia $\quad 6$

4- Dauzkazun gernu-galera hauek, zenbat kaltetzen dute zure bizi-kalitatea?

Mesedez adierazi borobil batez 0 (ez nau ezer kaltetzen) eta 10 (asko kaltetzen nau) bitarteko zenbaki bat

$\begin{array}{ccccccccccc}0 & 1 & 2 & 3 & 4 & 5 & 6 & 7 & 8 & 9 & \begin{array}{c}10 \\ \text { ezer ez }\end{array}\end{array}$

ICIQren puntuazioa: gehi itzazu 2, 3 eta 4galderetako puntuak =

5- Noiz galtzen duzu gernua? (adieraz ezazu zuri gertatzen zaizun guztia)

Inoiz ez duzu gernua galtzen

Komunera heldu aurretik galtzen duzu gernua

Eztula edo doministiku egitean galtzen duzu gernua

Lotan galtzen duzu gernua

Ariketa fisikoa edo kirola egitean galtzen duzu gernua

Gernu egiten bukatu eta jantzi ondoren gernua galtzen duzu

Arrazoi argirik gabe galtzen duzu gernua

Etengabeko gernu-galera duzu

Mila esker galdera hauei erantzuteagatik.

Gernu-inkontinentziak bizi-kalitatean duen eragina aztertzen da galdeketa labur batez.

\subsubsection{Miaketa fisikoa}

Tratamendu kontserbatzailea eta farmakologikoa hartu aurretik ez da zertan emakumezko guztietan azterketa fisikoa egin behar; bai sintoma ez-tipikoak edo zalantza diagnostikoak daudenetan bai eta hasierako tratamendu-planek porrot egin duten horietan ere. 
5.1.4.1. Orokorra: BMI eta emakumezkoaren osasun-egoera orokorra aztertzen da.

5.1.4.2. Neurologikoa: errain-sustraiak aztertzen dira batez ere, funtzio motorrak eta sentsorialak. Uzkiko erreflexua eta erreflexu bulbokabernosoa baloratuko ditugu, baita perineoko sentsibilitatea ere. Honako kasu hauetan egin beharko da: bat-bateko Gla agertzean (b.e. premiazkoa) eta sintoma neurologikoen agerpen berriaren aurrean.

5.1.4.3. Zoru pelbikoko muskuluen uzkurdura-gaitasuna: honetarako Oxford eskala erabili ohi dugu (4. taula).

5.1.4.4. Ginekologikoa: ehunen atrofia dagoen eta prolapso mota eta maila aztertzen dira. Orbainak, malformazioak eta pelbiseko masak dauden aztertu behar da.

5.1.4.5. Gernu-inkontinentziari zuzenduta: uretraren mugikortasuna eta ahaleginarekin agerturiko Gla ikuskatzea du helburu.

4. taula. Zoru pelbikoko muskuluen uzkurdura aztertzeko Oxford eskala (Laycok, 2002).

0/5 Uzkurdurarik eza
1/5 Oso uzkurdura ahula
2/5 Uzkurdura ahula
3/5 Bitarteko uzkurdura, tentsioduna eta iraunkorra
4/5 Uzkurdura ona. Tentsio iraunkorra erresistentziarekin.
5/5 Uzkurdura indartsua. Tentsio iraunkorra erresistentzia gogorrarekin.

Zoru pelbikoko muskuluen uzkurdura-indarra neurtzen du.

Esfortzu-proba: puxika beteta dagoela, emakumezkoari eztul egiteko eskatzen zaio, bai etzanda eta bai zutik ere. Uretratik gernu-galera ikuskatuz gero, EGI baten aurrean egongo gara ziurrenik. Test honen balio iragarle positiboa \% 78-97koa da (9). Emaitza negatiboa bada, puxika nahikoa beteta ez dagoelako izan daiteke, beraz, azterketa egin aurretik, puxika beteta dagoela ziurtatu beharko dugu (txizaren 300 ml-rekin dagoenean beteta kontsidera dezakegu).

Prolapsoa duten emakumeetan, esfortzu-proba prolapso hori zuzendu ostean egin behar da, prolapsoak berak Gla ezkutatzen duen jakiteko.

PGlaren kasuan, informazio gutxi helaraziko digu miaketa fisikoak.

5.1.4.6. Gernu egin osteko hondarra (GEOH). Txiza egin ostean puxikan gelditzen den gernu kantitatea da. Hau neurtzeak hustuketa-arazoak baztertzea errazten digu eta tratamenduaren aukeraketan ere laguntzen digu; hortaz paziente guztietan aztertzea gomendatzen da. Halere, EGI edo PGIko hasierako tratamendurako ez da ezinbestekoa, baina bai lagungarria baldin zalantza diagnostikoak badaude, hasierako tratamenduak porrot egin badu, edota txizaren erretentzioak edota gainezkako gernu-galerak kezkatzen bagaitu. GEOHa 100-150 ml-tik gorakoa denean patologikoa kontsidera daiteke. Ekografiaz neurtzea gomendatzen da, ez-inbasiboa, zehatza eta merkea delako (2 EM 2, B GG; 1. eranskina), formula sinple batzuekin, gero ikusiko dugun moduan. 


\subsubsection{Gernu-analisia}

Gla duten emakume guztietan egin behar da, infekzioa eta hematuria baztertzeko (zeinak patologia organikoaren susmoan jarriko gaituen). Analisi sistematiko bat egiten da, eta asaldurekin badago, urokultiboa.

\subsubsection{Gernu egitearen egunerokoa}

Anamnesiaren atal bat da, diagnostiko eta jarraipenean laguntzen diguna. Hauek lortzen ditu: gernu egitearen maiztasuna eta Glaren zenbatekoak identifikatzea, bai esfortzuzkoak bai eta premiazkoak ere, likidoen ahoratzea eta erabiltzen dituen babeskiak ezagutzea (5. taula).

5. taula. Gernu egiteari buruzko egutegia

\begin{tabular}{|c|c|c|c|c|c|c|}
\hline ordua & gernu egitea & premia & EGI & PGI & edaria & konpresa \\
\hline \multicolumn{7}{|l|}{$07.00-08.00$} \\
\hline \multicolumn{7}{|l|}{ 08.00-09.00 } \\
\hline \multicolumn{7}{|l|}{$09.00-10.00$} \\
\hline \multicolumn{7}{|l|}{$10.00-11.00$} \\
\hline \multicolumn{7}{|l|}{$11.00-12.00$} \\
\hline \multicolumn{7}{|l|}{$12.00-13.00$} \\
\hline \multicolumn{7}{|l|}{$13.00-14.00$} \\
\hline \multicolumn{7}{|l|}{$14.00-15.00$} \\
\hline \multicolumn{7}{|l|}{$15.00-16.00$} \\
\hline \multicolumn{7}{|l|}{$16.00-17.00$} \\
\hline \multicolumn{7}{|l|}{$17.00-18.00$} \\
\hline \multicolumn{7}{|l|}{$18.00-19.00$} \\
\hline \multicolumn{7}{|l|}{$19.00-20.00$} \\
\hline \multicolumn{7}{|l|}{$20.00-21.00$} \\
\hline \multicolumn{7}{|l|}{$21.00-22.00$} \\
\hline \multicolumn{7}{|l|}{$22.00-23.00$} \\
\hline \multicolumn{7}{|l|}{$23.00-24.00$} \\
\hline \multicolumn{7}{|l|}{$00.00-01.00$} \\
\hline \multicolumn{7}{|l|}{$01.00-02.00$} \\
\hline \multicolumn{7}{|l|}{$02.00-03.00$} \\
\hline \multicolumn{7}{|l|}{$03.00-04.00$} \\
\hline \multicolumn{7}{|l|}{$04.00-05.00$} \\
\hline \multicolumn{7}{|l|}{$05.00-06.00$} \\
\hline $06.00-07.00$ & & & & & & \\
\hline
\end{tabular}

Gernu egiteko egutegia. Pazienteak likido-ahoratzea, inkontinentzia eta motak adieraziko ditu, baita zenbatean behin eta zenbat txiza egiten duen ere.

\subsubsection{Konpresaren testa}

Galdutako gernu kantitatea aztertzen du.

Konplexutasunik gabeko kasuetan, oinarrizko ebaluazio honekin Glaren diagnostikoa egin dezakegu bai eta tratamendu ez-kirurgikoa jarri ere. 


\subsection{Ebaluazio espezializatua}

Oinarrizko asistentzia-maila batean konpondu ezin daitezkeen arazoak dituzten pazienteetan egin beharko da. Honako hauek lirateke espezialistarengana bidaltzeko irizpideak:

- Gernu-infekzioa baztertu osteko sabel edo pelbiseko mina.

- Gernuaren kultiboaz baieztaturiko infekzio errepikakorrak (>3 infekzio urtean).

- Gernu-infekzio gabeko hematuria gaiztotasunerako arrisku-faktoreekin.

- Bizitza osoko Gla edo maskuri-baginako fistula baten susmoa edota uretrako dibertikulua.

- Masa pelbikoa edo himena baino beheragoko prolapsoa.

- Sintoma neurologiko berriak.

- Zalantza diagnostikoak.

- Irradiazio pelbikoa edo berreraikitze-kirurgiaren aurrekaria.

- GEOHa behin eta berriz altua, iturburu posibleak tratatu ostean (adib. botikak, gorozkiinpaktazioa).

- Gainezkako inkontinentziaren susmoa.

- Gernu-zunda denbora luzez edo uretratik haren pasurako zailtasunak daudenean.

- Bat-bateko Gla.

\subsubsection{Ikerketa urodinamikoa}

Ikerketa urodinamikoa egiteko irizpideak hauek dira (1. irudia): tratamenduak porrot egitean, EGla kirurgiaz tratatu aurretik, sintoma konplexuak dituztenetan, kirurgiaren porrotaren edota konplikazioen aurrean eta gainezkako Gla susmatzean.

1. irudia. Urodinamia. Gernu-maskurian eta uzkian presioa neurtzeko zundak kokatzen dira eta bestalde zunda batekin maskuria urez betetzen da; presio- eta bolumen-aldaketak eta haien erlazioa aztertuz gernu-puxikaren funtzionamendua uler dezakegu.

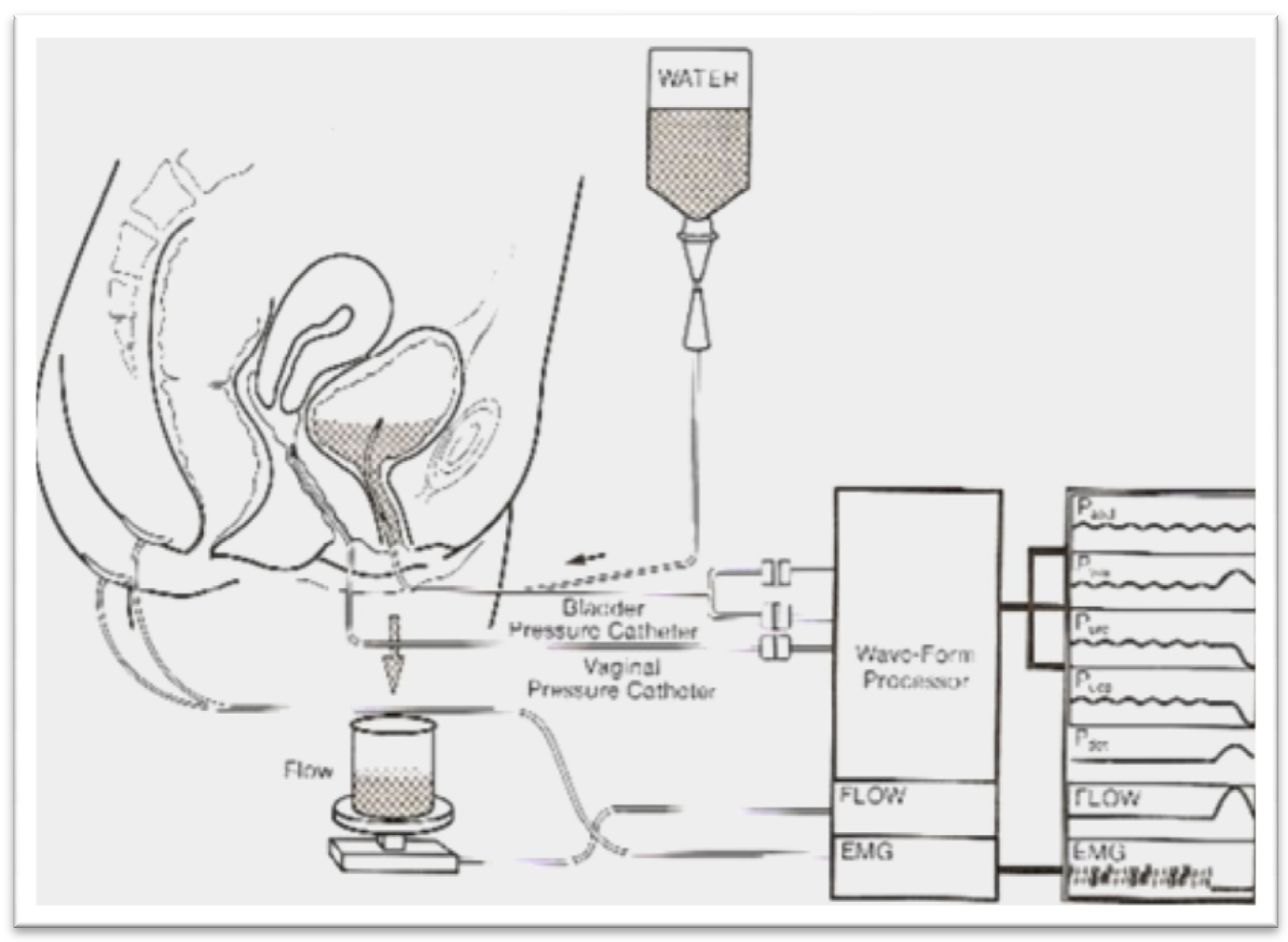

\subsubsection{Fluxumetria}

Berezko gernu egitean, bolumenaren eta denboraren arteko harremana aztertzen du. Hustuketa-arazoak antzeman ditzake. 


\subsubsection{Zistomanometria}

Bai maskuriaren betetze-fasean eta bai hustuketa-fasean bolumenaren eta presioaren arteko harremana atertzen du.

a) Betetze-proba: sentikortasuna, maskuriaren edukiera eta moldaera aztertzen ditu gernupuxikan, baita detrusorearen (gernu-maskuriko muskulu leuna) aktibitatea ere (uzkurdura ezborondatezkoak dauden ala ez ikus daiteke). Honako diagnostiko hauek egin ditzakegu betetze-probaren bitartez:

-- Detrusorearen hiperaktibitatea: muskulu honen nahigabeko uzkurdurengatiko Gla ikuskatzen dugunean.

-- EGI: sabeleko presioaren handipenarekin ikuskatutako gernu-galera.

-- GI mistoa: aurreko bi aurkikuntzak ikusi ditugunean.

GI motak ezberdintzen ditu beraz.

b) Hustuketa-proba: gernu egitean fluxua eta presioa aztertzen ditu, hustean detrusoreak duen jarrera aztertuz. Hustuketa-disfuntzioa badago, buxaduragatik edota detrusorearen aktibitate faltagatik den ezberdin dezake.

\subsubsection{Uretrozistoskopia}

Gernu-maskuriaren eta uretraren barrualdea ikustean datza endoskopia bidez, patologia organikoa ikus daitekeelarik. Mina edo hematuria daudenean eta txiza egiteko premiak eta maiztasunak tratamenduari erantzuten ez diotenean erabiltzen da.

\subsubsection{Irudi-teknikak}

Gaur egun ekografia eta erresonantzia magnetikoa dira erabilienak. Erresonantziak oso irudi anatomiko onak lortzen ditu, baina funtzio-azterketak egitea zailagoa da, gainera oso teknika garestia da. Aldiz, ekografia, merkea izateaz gain, denbora errealean funtzio-ikerketak egiteko oso baliagarria da.

Ekografia egiteko bide perineala da erabiliena zoru pelbikoaren azterketan. Haren erabilerak honakoak dira Glaren ikerketan:

- Hustuketa osteko gernu-hondarraren azterketa: erabilera garrantzitsuenetakoa. Makina bat formula deskribatu izan dira honetarako. Plano sagitalean diametro handiena neurtzen da $\mathrm{cm}$-tan, baita plano longitudinalean eta aurre-atzekoan ere. Gehien erabiltzen direnak hauek dira:

- Haylen: AxBx5.9 -14.6

- Dietz: AxBx5.6

- Dicuio: AxBxCx0.5

- Mallekin EGla tratatzeko kirurgia burutu ostean, haren kokapena eta ibilbidea zehazki kontrola ditzakegu ekografiaren bitartez, baita ahalegina egitean denbora errealean zer gertatzen den ikusi ere. Emaitza txar edo onak balora ditzakegu (genua galtzen duen ala ez, hurrenez hurren) eta konplikazio edo inkontinentziaren berragerpenaren aurrean erabakiak hartzen lagun diezaguke. 


\section{Tratamendua}

Gla sarritan azpitratatua izaten da; ikerketa batean, astean gutxienez behin gernu-galera pairatutako emakumeetatik \% 60k soilik jaso zuen horretarako tratamendua (10).

\subsection{Tratamendua jaso aurretik}

Inkontinentzia motaren arabera tratamendua ezberdina izango da, hortaz funtsezkoa da diagnostikoan GI mota zehazki zein den argi geratzea.

Tratamenduaren helburua pazientearen bizi-kalitatea hobetzea da. Pazienteari tratamenduaren arriskuak eta onurak azaldu behar dizkiogu berarekin erabakiak elkarrekin hartu ahal izateko. Argi eta garbi azaldu behar diegu emakume batzuei ez direla guztiz sendatuko, baizik eta hobekuntza nabari dezaketela beren sintomatologian.

Emakumezkoek jakin behar dute Gla ez dela adinaren ondorio normal bat eta badaudela horretarako konponbideak.

\subsection{Gernu-inkontinentziaren tratamendua}

Haren helburua sintomen arintzea da. Lehen mailako tratamendua edozein ingurune asistentzialetan egin daiteke; bigarren mailakoa, aldiz, unitate espezializatuetan, aurreko tratamenduak huts egiten duenean.

\subsubsection{Lehen mailako tratamendua}

\subsubsection{Tratamendu kontserbatzailea}

GI mota ezberdinen kasuan hasierako tratamendu kontserbatzailea antzekoa izango da, zehaztasun batzuekin.

Botikak eta kirurgia ez den edozein tratamendu dago barne. Teknika ez-inbasiboak dira, alboondorioetarako posibilitate baxudunak eta merkeak.

a) Faktore laguntzaileen aldaketa. Dituzten gaixotasunen eta hartzen dituzten botiken azterketa egingo dugu, baldintzaren bat hobe dezakegun ikusteko.

b) Bizitza-estiloaren aldaketa. Honi dagokionez, entsegu kliniko gutxi egin dira eta gehienek Gla orokorrean aztertzen dute mota zehatz batean zentratu gabe.

- Argaltzea: loditasuna Glrako arrisku-faktore independente bat da (1 EM) eta \% 5eko pisugaleraren ostean, badago Glaren hobekuntzaren ebidentzia, emakume lodietan argaltzea gomendatzen delarik (A GG). Ikerketek EGlaren kasuan PGlan baino onura handiagoak erakutsi dituzte zentzu horretan.

- Ikerketa-datu batzuen arabera badirudi lanean pisu handiak altxatzen dituzten emakumeek prolapso eta Gla pairatzeko erraztasun gehiago daukatela (3 EM).

- Ariketa fisiko moderatuak Glaren intzidentzia gutxitzen du adin ertain eta nagusiko emakumeetan, beharbada pisuaren kontrolagatik (3 EM).

- Dieta-aldaketak: gernu egitearen egunerokoak pazientearen likido-ahorakina ezagutzea baimentzen digu. Likido asko edaten duten emakumeetan gomendatuta dago gutxitzea ( $\mathrm{B}$ $\mathrm{GG}$ ); izan ere,\% 25 jaitsiz gero, gernu-kontinentzia hobetzen da (2 EM, B GG).

Tamaina txikiko lagindun entsegu klinikoetan aurkitutako datuen arabera, badirudi kafeinaren ahoratzearen murrizketak gernu egiteko maiztasuna, premiatasuna eta PGla hobetzen dituela (2 EM). Gainera, nokturia duten emakumeetan afalosteko edota arratsaldearen azken orduetatik aurrera likidoen ahoratzea ekiditea gomendatzen da (11). 
- Tabakoa erretzea: tabakoa uzteak Glaren maiztasuna gutxitzen du eta gernu egitearen maiztasuna gutxi dezake (biak $3 \mathrm{EM}, \mathrm{C} \mathrm{GG}$ ).

- Fisioterapia.

Zoru pelbikoko muskuluen (ZPM) osotasuna guztiz garrantzitsua da gernu-kontinentzian, horregatik haien entrenamendua funtsezko prebentzio-neurri bat da. ZPMen uzkurdura aktiboaz ariketa erregularra egitean datza. Batez ere EGlaren kasuan dira eraginkorrak.

Berrikuspen sistematikoek ariketa horiek egitea eraginkorra dela ikusi dute gernu-inkontinentzia sendatzeko edota sintomak hobetzeko (\% 55 vs 3, RR 17.3, Cl 4.3-69.6) (12).

Ariketak gainbegiratuak direnean, emakumeak bere kontu egiten dituenean baino eraginkorragoak dira (1 EM), edozein urterekin egin daitezkeelarik (A GG). Hasierako miaketan baginako ukipenaren bidez ZPMak nahita uzkurtu eta erlaxatzeko gaitasuna aztertzen da eta banakako entrenamendu-programa ezartzen da.

Kono baginalek ZPMen errehabilitazioak eskaintzen dituen emaitza berberak dituzte (1 EM), baina zeharkako efektuak aurkez ditzakete eta paziente batzuetan ezegokiak suertatu; beraz, ZPMen errehabilitazioa gomendatzen da paziente guztietan lehen tratamendu bezala, eta konoak ondo toleratzen dituzten emakumeetan hasierako tratamendua izan daitezke (B GG). EGI arin-moderatua eta jokaera egokia duten emakumeetan eraginkorragoak dira (3 EM) (11).

Konoak eta biofeedback-a erabilgarriak dira emakumeek ez dituztenean beren ZPMak zuzen identifikatzen.

Intentsitate baxuko elektroestimulazio baginala ere aproposa da PGlarentzat (2 EM, B GG); halere, tratamendu hori ez da ZPMen errehabilitazioa baino eraginkorragoa.

Haurdunaldi eta erditzea Gla pairatzeko arrisku-faktoreak dira. Haurdunaldian burututako ZPMen ariketek Gla prebeni dezakete; erditu osteko hirugarren hiletik aurrera Gla agertuz gero, ZPMen ariketak egitea gomendatzen da (1 EM, A GG), eta 4.000 g edo gehiagoko umea erditu duten edota forzeps bitarteko erditzea izan dutenetan erditu eta jarraian egitea (C GG) (11).

\section{- Maskuriaren entrenamendua}

Maskuriaren berreziketa: PGlaren sintomak hobetzen ditu (1 EM), EGlan baino eraginkorragoa izanik.

Gernu egiteko ohituren heziketan datza, maskuriaren kontrola berreskuratzeko. Modurik ohikoena gernu-egite programatuak dira: gernu egiteko egunerokoan oinarriturik gernu-egiteen arteko hasierako tartea zehazten da, momentu horretan pazienteak txiza egin behar duelarik gogoa izan ala ez. Aste batean zehar pazientea gai denean tarteak errespetatzeko txiza-galerarik gabe, horiek 15-30 minutu luzatzen dira tarte normaletara heldu arte (normalki 3-4 ordukoak) (A $\mathrm{GG})$.

6 aste bitartean irauten du tratamendu honek eta pazienteek, hasieran batez ere, erantzun faltagatik, motibazio handia behar izaten dute.

Maskuriaren berreziketa ZPMen ariketekin elkartuta, bata edo bestea bere kabuz erabilita baino eraginkortasun altuagoa lortzen da epe laburrean EGI eta GI mistoaren kasuan (2 EM, B GG) (11).

\section{- Idorreria kronikoa}

Gla oker dezake eta gernu-erretentziorako arriskua handitzen du, beraz saihestea gomendatzen da. 


\section{- Gailuak}

EGlan dira erabilgarri. Euskarri bezala erabiltzen diren gailuen artean kontinentziarako pesarioak dira ohikoenak. ZPMen ariketekin konbinazioan ere erabil daitezke. Asetze globalaren tasa urtebeteren buruan \%50ekoa da (13). Ginekologo edota urologo batek ezar ditzake eta bai pazienteak berak ere erakutsiz gero.

\subsubsection{Premiazko gernu-inkontinentziaren tratamendu farmakologikoa}

Tratamendu kontserbatzaileak huts egiten duenean, PGla daukaten emakumeetan egokia da. Halere, paziente batzuek zuzenean tratamendu farmakologikoarekin hasi nahi dute, eta hala egin dezakete; botikak tratamendu kontserbatzailearekin elkartuz gero, edozein neurri bere aldetik erabilita baino eraginkortasun handiagoa lortzen da dena den.

2 botika-talde ditugu:

\section{a) Antagonista muskarinikoak}

Maskuriaren muskulu detrusorearen nahigabeko uzkurdurak inhibitzea da haien helburua. Espainian erabilgarri ditugunak hauexek dira: tolterodina, solifenazina, fesoterodina, trospio kloruroa, propiberina eta oxibutinina; guztiek dute $1 \mathrm{EM}$ eta A GG, eta guztien eraginkortasuna berdina dela uste da. Denak administratzen dira aho bidez oxibutinina izan ezik, zeina azalaren bidez administratzen baita, gibeleko lehen pausoa saihestuz eta zeharkako efektuak murriztuz, nahiz eta beste albo-ondorio batzuk izan ditzakeen, adibidez azaleko erreakzioak.

Albo-ondorioak maiztasun gutxikoak dira: ahoko lehortasuna, idorreria eta ikusmen lausoa; tratamendua uztearen arrazoi nagusia dira eta horrexegatik garrantzi handikoa da pazienteari honetaz hitz egitea, baita 4 aste pasatu arte balitekeela onurarik oraindik ez nabaritzea.

Plazeboarekin alderatuz, onura xumea daukate PGlan. Sendatze-tasa baxua da, \% 49koa (14).

\section{b) Hartzaile adrenergikoen agonistak}

Mirabegron izeneko farmakoa dugu hemen. Beta-3 hartzaile adrenergikoen agonista da eta Europan daukagu 2013tik. Eraginkorra da PGlaren tratamendurako (1 EM, A GG). Ondo jasaten da eta aho sikua saihesten du, zeina antikolinergikoen albo-ondorio bat den.

Haren eraginkortasuna antimuskarinikoen antzekoa da.

Hipertentsio larri ez-kontrolatua daukaten emakumeetan kontraindikatua dago (180/110 $\mathrm{mmHg}$ zifrak edo handiagoak) eta tentsio arteriala igo dezake, beraz horren kontrola egin behar da tratamenduaren aurretik eta horretan zehar.

Tratamenduarekiko atxikidurari dagokionez, 21.996 pazientedun ikerketa batek (emakumez eta gizonez osatua) urtebeteren buruan tratamenduaren iraunkortasuna mirabegronen kasuan handiagoa zela frogatu zuen antimuskarinikoekin konparatuta (15).

Farmako antimuskariniko bat mirabegronekin batera erabil daiteke farmako bat soilik eraginkorra izan ez denean edota albo-ondorioengatik erabili ezin izan denean. Konbinazioa banaka erabiltzea baino eraginkorragoa da.

\section{c) Estrogeno topikoak}

Bai PGlaren bai EGlaren kasuan, menopausian atrofia genitala daukaten emakumeetan onuragarria izan daiteke; bagina bidez administratzen dira estrogenoak eta 3 hilabete edo gehiago eman ditzake pazienteak onura sentitu arte. Xurgapen sistemikoa baxua da eta 7 
urtetan zeharkako ikerketa batek ez zuen arrisku kardiobaskular edota minbizien handipenik behatu estrogeno topikorik erabiltzen ez zuten emakumeekin alderatuta (16).

Emakumeak ez badu bigarren farmako bat probatu nahi, edota hobe, 2 saiakera eta konbinazioa probatu ondoren, hobekuntza nahikorik ez badu nabari, bigarren mailako tratamendua eskain diezaiokegu. Horretarako unitate espezializatu batera bidaliko dugu, eta bertako proba diagnostikoek esango dute tratamendu hauek ondo letozkiokeen ala ez.

\subsubsection{Bigarren mailako tratamendua}

Ondoren azaldutakoak PGla duten pazienteetan erabiltzen dira, lehen mailako tratamenduak porrot egindakoan.

\subsubsection{Toxina botulinikoa}

Maskuria hiperaktibo idiopatikoa duten pazienteetan erabiltzeko onetsitako toxina bakarra "Onabotulintoxina» da (Botox $\left.{ }^{\circledR}\right) .2$ ikerketa aleatorizatutan, eraginkortasunean ezberdintasun esanguratsua aurkitu da plazeboarekin alderatuz PMlaren sintomak sendatu edota hobetzeko (1 EM). Teknika honen GG: A.

Zistoskopia bidez toxina injektatzen da muskulu destrusorearen paretan.

Haren albo-ondorioak honako hauek dira: gernu egin osteko hondar altua, zeinak norberak egindako zundaketa behar izan dezakeen denbora batez, eta bakteriuria (1 EM). Horrexegatik teknika hau saihestuko dugu gernu egin osteko hondar altua izateko arriskuan dauden pazienteetan (baldin eta norberak egindako zundaketa egiteko prest ez badaude) eta gernuinfekzio errepikakorrak dauzkaten pazienteetan (11).

Prozedura eraginkorra izan bada, denborarekin sintomak berragertu ohi dira, baina birtratamendua normalki eraginkorra izaten da (3 EM).

Teknika hau mediku espezializatu batek egin behar du, prozedura honetan jantzia dagoenak eta esperientziadunak.

\subsubsection{Atzeko nerbio tibialaren estimulazioa}

PMla daukaten pazienteetan eraginkorra izan daiteke (17). Orkatilaren barneko aurpegian akupunturako orratz bat jartzen da eta estimulazio elektrikoa administratzen da.

Errebisio sistematikoek \% 60ko eraginkortasuna frogatu dute (antikolinergikoen antzekoa), eta albo-ondorioen tasa baxua. Uzteko arrazoi nagusia eraginkortasun falta da.

\subsubsection{Errain-neuromodulazioa}

Estimulazio elektrikoa erabiltzen duen prozedura bat da eta S3 foramenean berunezko kable bat ezartzean datza, zeina behin-behineko estimulazioko gailu batera konektatua dagoen. Bi fase ditu: proba eta ezarpena.

Hasierako fasean gernu egitearen egunerokoa bete behar du pazienteak 2 astetan zehar, eta horren buruan sintometan behatutako hobekuntza \% 50 baino gehiagokoa bada, behin betiko gailuaren ezarpenera jotzen da ipurmasailaren parte altuenean.

Ikerketa batzuek \% 60-90eko hobekuntza-tasak deskribatu zituzten eta \% 30-50eko sendatzetasak (18). Eragin hori 5 urte baino luzeago mantentzen dela dirudi (3 EM). Teknika honen GG: A.

Albo-ondorioak aurkeztea ohikoa da, kirurgiaren beharra duten horiek barne, eta 5 urteren buruan pazienteen herenari gertatzen zaio, gailuaren disfuntzioagatik edota eraginkortasunik ezagatik. 
Hau ere mediku espezializatu batek egin beharreko teknika da.

Beraz, bigarren mailako PGlarentzako tratamenduen artean gomendagarrienak toxina botulinikoa eta errain-neuromodulazioa dira, bata edo bestea erabiliko dugularik kasu bakoitza banaka aztertu eta gero.

\subsubsection{Esfortzuzko gernu-inkontinentziaren tratamendu kirurgikoa}

Sabeleko presioa handitzean, esfortzu fisiko bat egitean, nahigabe ematen diren gernu-galerak konpontzeko bideratuta daude, EGIrako. Kirurgia hau uretraren azpialdean euskarria ematean datza eta tratamendu kontserbatzaileak huts egindakoan erabiltzen da; bestalde, badaude paziente batzuk konponbide azkar eta eraginkor baten bila. Horiek kirurgiaren arriskuak onartuz gero, hau lehen aukera izan daiteke.

Kirurgiaren sendatze-tasak altuak dira. Teknika ugari daude EGlaren kirurgiarako. Azken hamarkadetan prozedura berriak sortu dira, emaitza onekin epe labur eta luzean. Lehenengoa 1961ean Burch-ek deskribatutako teknika edo pubis atzeko kolposuspentsioa izan zen, zeina urte askotan zehar EGlaren tratamendurako gold standard-a izan den. Uretraren alboko ehunak Cooper izeneko lotailura zintzilikatzean datza. Eraginkorra da A GGarekin. 1995. urtean, Ulmsnten-ek «tentsio gabeko uretra azpiko xingola» izeneko kontzeptua jaurtiki zuen, pubis atzekoa.

Xingolak polipropilenozko sare-begiak dira, monofilamentu makroporotsu (1 motakoak) eta bagina bidez ezartzen dira.

Gaur egun xingolak dira erabilienak, uretraren erdiko atalaren azpian ezartzen dira eta pelbiseko egituretan finkatzen dira uretrari eusteko. Epe luzerako emaitza onak dituzten eta minimoki inbasiboak diren teknikak ikertzen eta lortzen doaz denboran zehar, horrela xingola-mota desberdinak daude:

- Pubis atzeko uretra azpiko xingola. Pubisaren atzeko espazio anatomikoa zeharkatzen du eta sabel-paretatik kanporatzen da pubisaren gaineko gunean (2. irudia).

- Obturatzailean zeharreko uretra azpiko xingola. 2 zulo obturatzaileetan zehar finkatzen dira eta iztaietako azala zeharkatuz kanporatu (3. irudia).

- Ebaki bakarreko uretra azpiko xingola. Aurrekoak baino laburragoa da $(8 \mathrm{~cm}, 40 \mathrm{~cm}$ izan beharrean). Baginan ebaki bakarra behar du eta finkapena pubis atzekoa edota obturatzailean zeharrekoa izan daiteke.

2. irudia. Pubis atzeko xingola.

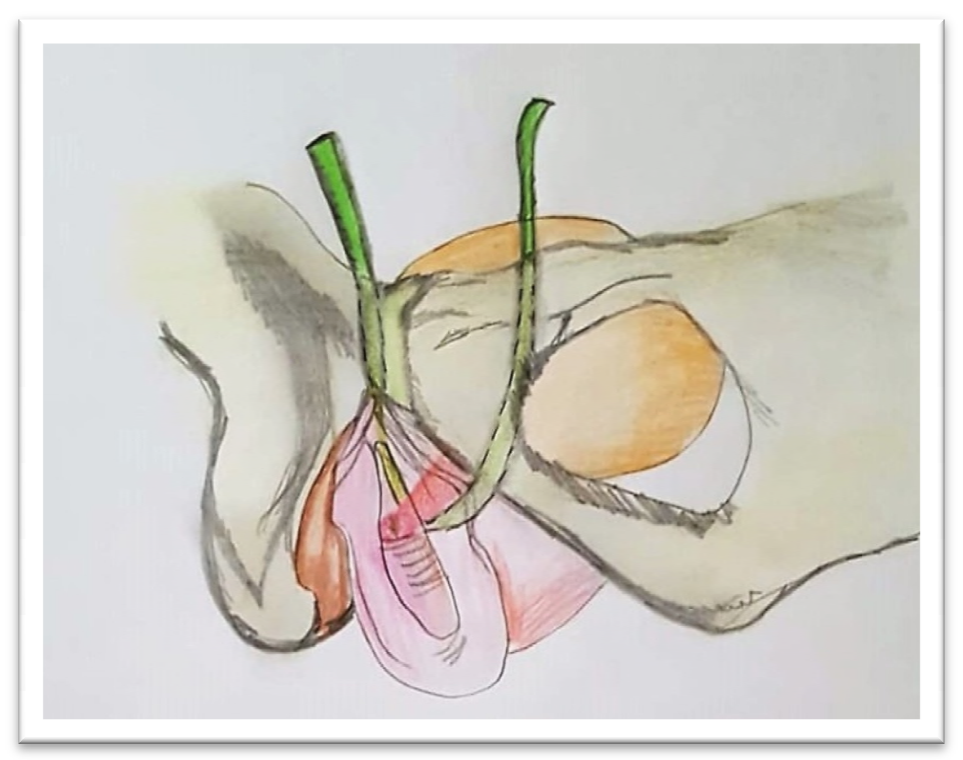


3. irudia. Obturatzailean zeharreko xingola.

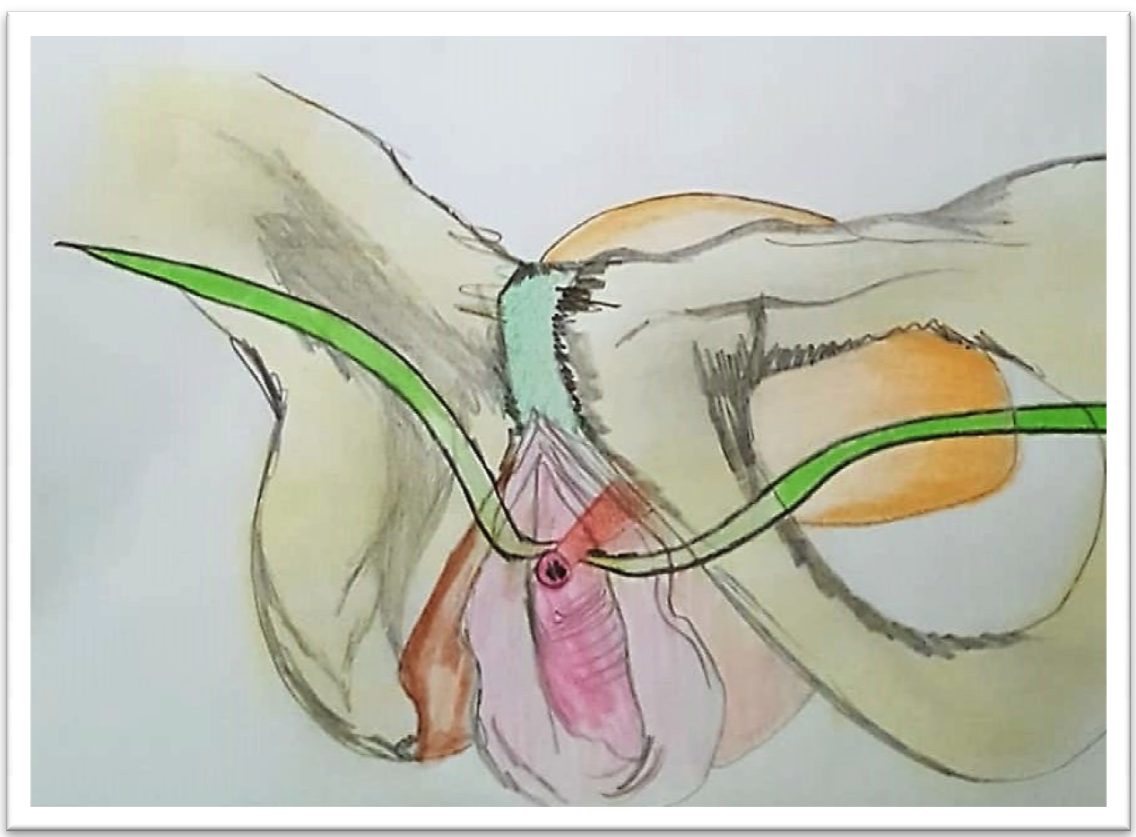

a) Uretra azpiko xingolak (pubis- atzekoak eta obturatzailean zeharrekoak) Lehenengoz pubis atzeko xingolak deskribatu ziren eta urte batzuk geroago obturatzailean zeharrekoak, pubis atzeko bideak dituen konplikazioak ekidinez. 2001. urtean Delorme-k obturatzailean zeharreko teknika «kanpotik barrura» deskribatu zuen, eta, 2003an, de Leval-ek, «barrutik kanpora».

Xingola Burch-en teknika bezain eraginkorra da eta baditu hainbat abantaila: ebakuntzadenbora, ospitaleko egonaldia eta eguneroko ekintzetara bueltatzeko beharrezko denbora laburragoak. Badaude haien konplikazioetan ezberdintasun batzuk: huste-disfuntzioa maizago agertzen da Burch-en teknikarekin, eta maskuriaren zulaketa, xingolarekin (1-2 EM) (11).

Xingolei dagokienez, pubis atzekoak eraginkorrak dira eta epe luzerako emaitza onak aurkezten dituzte (A GG); obturatzailean zeharrekoek beste tekniken antzeko eraginkortasuna erakutsi dute epe labur eta erdian (1-2 EM), epe luzerako datuak falta diren arren.

Xingolen konplikazioei dagokienez, orokorrean ohikoagoak dira pubis atzekoan: maskuriaren nahigabeko zulaketa, xingolagatiko urradura baginan, huste-disfuntzioa edota odolbatua adibidez. Aldiz, obturatzailean zeharrekoan ohikoagoa da ebakuntza osteko mina izter edo iztaian, epe laburrean (\% 12 vs \% 2, 17 ikerketez osatutako metaanalisi batean) (19). Gainera, sexu-harremanetako minaren tasa altuagoa da obturatzailean zeharrekoekin, nahiz eta ikerketa gehiago beharrezkoak diren xingola mota desberdinek sexu-funtzioan duten eragina aztertzeko.

Xingolen inguruan badira ikerketa ugari haien emaitzak aztertzeko. Eraginkortasunari dagokionez, biena antzekoa dela dirudi. 8.600 paziente barne zituzten 55 entsegu errandomizaturen errebisio sistematiko eta metaanalisi batean, urtebeteren buruan antzeko sendatze-tasa objektibo eta subjektiboa argitaratu zen, sendatze-tasa \% 62-98koa izan zelarik obturatzailean zeharreko xingolarentzat eta \% 71-97koa pubis atzekoarentzat (19).

8.600 emakume daniarrekin eginiko 5 urteko kohorte-ikerketa baten, obturatzailean zeharreko xingolekin berrebakuntzaren behar bikoitza deskribatu zen (20); ondorengo 
ikerketa batek \%6ko tasa argitaratu zuen pubis atzeko xingolari dagokionez, \%9rekin alderatuta obturatzailean zeharrekoan.

Bestalde, beste ikerketa bateko emakumeen \% 29k berriz agertutako PGla deskribatu zuen kirurgiaren ostean, tratamendu farmakologikoa behar izan zuena, eta \% $4 \mathrm{k}$ hustuketadisfuntzio iraunkorra.

Beraz, xingola desberdinen artean eraginkortasuna antzekoa da, baina konplikazio mota ezberdinak aurkezten dituzte, eta hori jakinda, pazienteak eta kirurgialariak erabaki behar dute kasu bakoitzean zein erabili.

\section{b) Ebaki bakarreko xingolak}

Tentsio gabeko xingolen kontzeptu berdina mantenduz, uretra azpiko baginan ebaki txiki bat eginda burutzen da teknika hau, gune anatomiko guztiak zeharkatu gabe, muskulu obturatzailean edo haren faszian finkaturik. Konplikazioak ekiditeko sortu da eta ez dira xingola klasikoak baino txarragoak epe labur eta ertainean (2 EM); ebakuntza osteko min gutxiago deskribatu da eta beste albo-ondorioetan tasa berdina. Xingola hau, gaur egun, aukera bat da, epe luzerako datuak falta direla pazienteari adierazi ostean (B GG).

Ikerketa gehienek EGlarentzako \% 74-95eko sendatze-tasak deskribatu dituzte ebakuntza eta 6-12 hilabetera, baina epe luzeko ikerketak urriak dira (21). 15 entsegu errandomizaturen errebisio sistematiko eta metaanalisi batek xingola klasikoak eta ebaki bakarrekoak konparatu zituzten eta lehenengoetan sendatze objektibo eta subjektiboen tasak esanguratsuki hobeak izan ziren. Konklusio zehatzagoak erauzteko kalitatezko ikerketak beharrezkoak dira.

\section{c) Xingola estugarriak}

Beren tentsioa estutzea ahalbidetzen dute ebaketa ostean. Ez dago konparatzeko daturik eta hauetako xingola bat, "Remeex» deitua, 38 pazientetan ikertua izan zen. Pazienteok uretraren esfinterraren akatsa zuten eta ikerketa bukatutakoan guztiak zeuden sendatuta EGlari dagokionez.

\section{d) Uretra inguruko injektagarriak}

Uretraren inguruan gai zabaltzaileak injektatzen dira, uretraren paretek ixte estuago bat izan dezaten.

Kirurgiak baino emaitza eskasagoak dauzka (3-4 EM) eta denborarekin haren eraginkortasuna murriztuz doa, hura mantentzeko injekzio berriak behar dituelarik (2 EM). Konplikazio-tasa nahiko baxua da.

Paziente hautatu batzuentzat aukera bat lirateke teknikaren epe luzerako emaitzen gabeziaz berri eman ostean (B GG) (11).

\section{e) Esfinter artifiziala}

Esfinter artifizial bat kokatzen da uretran. Epe laburrean eraginkorra dirudien arren, datu oso gutxi daude teknika honen inguruan eta haren iraunkortasuna ez dago frogatua, gainera konplikazio anitz ditu ( $3 \mathrm{ME})$, beraz, beste teknikek huts egin duten pazienteentzat gordetzen da gomendio egoki baten ostean (C GG).

Konklusio gisa, bai Burch-en teknikak, bai pubis atzekoak bai obturatzailean zeharrekoak antzeko eraginkortasuna dute (A GG hirurek), baina konplikazio-tasa baxuagoa denez, xingolak aukerako teknikak dira gaur egun. Ebaki bakarreko xingolak beste aukera bat lirateke, epe luzerako daturik ez dugula pazienteari adierazita (B GG hauentzat). 


\section{f) Gernu-inkontinentzia mistoa}

Tratamendu kontserbatzailearekin hasiko gara, eta, eraginkorra ez bada, sintoma nagusiak gidatuko du tratamendua; hala, gernu egiteko premia bada sintoma nagusia, farmakoak erabiliko ditugu, eta, aldiz, EGla bada sintoma nagusia, kirurgiara joko dugu.

Kirurgiaren ostean, emaitza txikiagoa da EGla soilik aurkezten denean baino. Gainera, batzuetan kirurgiarekin PGlaren sintomak hobe daitezkeen arren, baliteke txarrera egitea ere, horrexegatik garrantzitsua da pazienteak era egokian aholkatzea tratamendu desberdinekin itxaron ditzaketen emaitza errealei buruz hitz eginez.

\section{Erreferentziak}

1. Rogers RG. Clinical practice. Urinary stress incontinence in women. N Engl J Med 2008; 358:1029.

2. Nygaard I. Clinical practice. Idiopathic urgency urinary incontinence. N Engl J Med 2010; 363:1156.

3. Morrill M, Lukacz ES, Lawrence JM, Nager CW, Contreras R, Luber KM. Seeking healthcare for pelvic floor disorders: a population-based study. Am J Obstet Gynecol 2007 Jul;197(1):86.e16.

4. Coyne KS, Sexton CC, Irwin DE, Kopp ZS, Kelleher CJ, Milsom I. The impact of overactive bladder, incontinence and other lower urinary tract symptoms on quality of life, work productivity, sexuality and emotional well-being in men and women: results from the EPIC study. BJU Int 2008;101(11):1388-95.

5. Brown JS, Vittinghoff E, Wyman JF, Stone KL, Nevitt MC, Ensrud KE, Grady D. Urinary incontinence: does it increase risk for falls and fractures? Study of Osteoporotic Fractures Research Group. J Am Geriatr Soc 2000 Jul;48(7):721-5.

6. Subak LL, Richter HE, Hunskaar S. Obesity and urinary incontinence: epidemiology and clinical research update. J Urol 2009; 182(6 Suppl):S2-7.

7. Subak LL, King WC, Belle SH, Chen JY, Courcoulas AP, Ebel FE, Flum DR, Khandelwal S, Pender JR, Pierson SK, Pories WJ, Steffen KJ, Strain GW, Wolfe BM, Huang AJ. Urinary Incontinence Before and After Bariatric Surgery. JAMA Intern Med 2015;175(8):1378-87.

8. Al-Mukhtar Othman J, Åkervall S, Milsom I, Gyhagen M. Urinary incontinence in nulliparous women aged 25-64 years: a national survey. Am J Obstet Gynecol 2017; 216(2):149.e1149.e11.

9. Harvey MA, Versi E. Predictive value of clinical evaluation of stress urinary incontinence: a summary of the published literature. Int Urogynecol J Pelvic Floor Dysfunct 2001; 12(1):31-7.

10. Harris SS, Link CL, Tennstedt SL, Kusek JW, McKinlay JB. Care seeking and treatment for urinary incontinence in a diverse population. J Urol 2007;177(2):680-4.

11. Sociedad Española de Ginecología y Obstetricia. Guias de Asistencia Práctica. Tratamiento de la incontinencia urinaria de esfuerzo. Tratamiento de la incontinencia urinaria de urgencia y del síndrome de vejiga hiperactiva. 2018. www.sego.es.

12. Dumoulin C, Hay-Smith EJ, Mac Habée-Séguin G. Pelvic floor muscle training versus no treatment, or inactive control treatments, for urinary incontinence in women. Cochrane Database Syst Rev 2014;10:CD005654.

13. Richter HE, Burgio KL, Brubaker L, Nygaard IE, Ye W, Weidner A, Bradley CS, Handa VL, Borello-France D, Goode PS, Zyczynski H, Lukacz ES, Schaffer J, Barber M, Meikle S, Spino C. Pelvic Floor Disorders Network. Continence pessary compared with behavioral therapy or combined therapy for stress incontinence: a randomized controlled trial. Obstet Gynecol 2010; 115(3):609-17.

14. Riemsma R, Hagen S, Kirschner-Hermanns R, Norton C, Wijk H, Andersson KE, Chapple C, Spinks J, Wagg A, Hutt E, Misso K, Deshpande S, Kleijnen J, Milsom I. Can incontinence be cured? A systematic review of cure rates. BMC Med 2017; 15(1):63.

15. Chapple CR, Nazir J, Hakimi Z, Bowditch S, Fatoye F, Guelfucci F, Khemiri A, Siddiqui E, Wagg A. Persistence and Adherence with Mirabegron versus Antimuscarinic Agents in Patients with 
Overactive Bladder: A Retrospective Observational Study in UK Clinical Practice. Eur Urol 2017; 72(3):389-399.

16. Crandall CJ, Hovey KM, Andrews CA, Chlebowski RT, Stefanick ML, Lane DS, Shifren J, Chen C, Kaunitz AM, Cauley JA, Manson JE. Breast cancer, endometrial cancer, and cardiovascular events in participants who used vaginal estrogen in the Women's Health Initiative Observational Study. Menopause 2018; 25(1):11-20.

17. Finazzi-Agrò E, Petta F, Sciobica F, Pasqualetti P, Musco S, Bove. Percutaneous tibial nerve stimulation effects on detrusor overactivity incontinence are not due to a placebo effect: a randomized, double-blind, placebo controlled trial. J Urol 2010; 184(5):2001-6.

18. Yamanishi T, Kaga K, Fuse M, Shibata C, Uchiyama T. Neuromodulation for the Treatment of Lower Urinary Tract Symptoms. Low Urin Tract Symptoms 2015;7(3):121-32.

19. Ford AA, Rogerson L, Cody JD, Ogah J. Mid-urethral sling operations for stress urinary incontinence in women. Cochrane Database Syst Rev 2017;7 :CD006375.

20. Kenton K, Stoddard AM, Zyczynski H, Albo M, Rickey L, Norton P, Wai C, Kraus SR, Sirls LT, Kusek JW, Litman HJ, Chang RP, Richter HE. 5-year longitudinal followup after retropubic and transobturator mid urethral slings. J Urol 2015;193(1):203-10.

21. Schellart RP, Oude Rengerink K, Van der Aa F, Lucot JP, Kimpe B, de Ridder DJ, Dijkgraaf MG, Roovers JP. A randomized comparison of a single-incision midurethral sling and a transobturator midurethral sling in women with stress urinary incontinence: results of 12-mo follow-up. Eur Urol 2014;66(6):1179-85.

ESKERRAK: Mikel Goitiari, erakutsitakoagatik eta gai honetan nire ilusioa pizteagatik.

\section{*1. eranskina}

EM: ebidentzia-maila

1 Gutxienez, entsegu kliniko kontrolatu aleatorizatu bat, diseinu egokiarekin.

2 Entsegu kliniko kontrolatuak, ongi diseinatuak, baina aleatorizatu gabe; kohorte-ikerketak edo kasu-kontrol ikerketak, ondo diseinatuak eta batez ere multizentrikoak; denboran zehar alderaturiko askotariko serieak, interbentzioaz edo gabe, eta emaitza harrigarriak esperientzia ez-kontrolatuetan.

3 Esperientzia klinikoan oinarritutako iritziak, deskribapeneko ikerketak, ikuskapen klinikoak edota jakitunen batzordeen txostenak.

GG: gomendiorako gradua

A Erabat gomendagarria

B Gomendagarria

C Ez da gomendatzen, eta ez da ez erabiltzea aholkatzen ere 
8

ธัง 